\title{
POSTOPERATIVE INFECTIONS FOLLOWING CARDIAC SURGERY
}

\author{
Jaya Lalwani ${ }^{1}$ \\ ${ }^{1}$ Associate Professor, Department of Microbiology, Gandhi Medical College, Bhopal.
}

\begin{tabular}{l}
\hline ABSTRACT \\
\hline BACKGROUND \\
$\begin{array}{l}\text { Postoperative infections following cardiac surgery are associated with life-threatening complications and prolonged } \\
\text { hospitalisation. This in addition to increasing patient morbidity and mortality also proves to be an economic burden to patients } \\
\text { and healthcare system. }\end{array}$
\end{tabular}

\section{MATERIALS AND METHODS}

This study was conducted with a view to identify the spectrum of postoperative infections in cardiac surgery patients along with studying the common bacterial isolates and the risk factors associated with the development of infections.

\section{RESULTS}

The incidence of postoperative infections in these patients was found to be $22 \%$ with surgical site infections being the commonest. The other infections observed were urinary tract, respiratory and bloodstream infections. The commonest bacterial isolate was Pseudomonas aeruginosa followed by Staphylococci and enteric gram-negative bacilli. In the analysis of risk factors age $>45$ years, obesity, surgery for coronary artery bypass grafting, operative time of $>6$ hours and mechanical ventilation for $>6$ hours were associated with increased risk of infection.

\section{CONCLUSION}

Infections following cardiac surgeries are important cause of postoperative morbidity. Their prevention by reducing modifiable risk factors and implementing proper infection control practices seems to be a best course of action.

\section{KEYWORDS}

Postoperative Infections, Cardiac Surgery, Surgical Site Infections, Risk Factors.

HOW TO CITE THIS ARTICLE: Lalwani J. Postoperative infections following cardiac surgery. J. Evolution Med. Dent. Sci. 2017;6(55):4146-4149, DOI: 10.14260/Jemds/2017/898

\section{BACKGROUND}

Cardiac surgeries have become one of the routinely performed surgeries in India. Postoperative infections can ruin the best of surgeries because of associated lifethreatening complications. ${ }^{(1)}$ Patients undergoing cardiac surgery are at increased risk for the developing nosocomial infections due to presence of multiple surgical wounds and frequent use of invasive devices for postoperative monitoring.(2,3) Postoperative infections not only prolong the hospital stay and recovery time, but they also increases the out of pocket expenditure associated with such procedures. Postoperative infections may take many forms viz. surgical site infection, mediastinitis, respiratory tract, urinary tract and blood stream infections.(1)

In spite of numerous advances in reconstructive surgical techniques, the infections following cardiac surgeries are difficult to treat.(4) It is therefore imperative to implement adequate measures to reduce these infections. To this end, it is necessary to identify epidemiological risk factors for postoperative infection following cardiac surgery.(1)

Financial or Other, Competing Interest: None.

Submission 19-05-2017, Peer Review 27-06-2017,

Acceptance 03-07-2017, Published 10-07-2017.

Corresponding Author:

Dr. Jaya Lalwani,

Associate Professor

Department of Microbiology,

Gandhi Medical College,

Royal Market, Bhopal.

E-mail: drjaya_is@yahoo.co.in

DOI: $10.14260 /$ jemds $/ 2017 / 898$

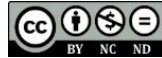

This study was conducted with objective to determine the spectrum of postoperative infection associated with cardiac surgery in term of their anatomical location, bacteriological profile and antibiotic sensitivity. We also assessed the determinants of postoperative infection following cardiac surgery.

\section{MATERIALS AND METHODS \\ Study Design \\ This was a descriptive study.}

\section{Study Duration}

Total duration of surgery was one year. The period of data collection was six months.

\section{Study Setting}

The present study was conducted in a tertiary care hospital of western India.

\section{Study Participants}

Patient of all age groups and both gender undergoing major and minor cardiac surgery in the institute.

\section{Exclusion Criteria}

Person operated at other institute and referred to index institute for any reason.

\section{Sample Size}

All patients who fulfilled the selection criteria for study participants during the period of data collection were included in the study. Following this, data was collected from a total of 100 patients. 


\section{Sample Collection}

Clinical samples viz. blood, sputum, urine and secretions from site of surgery were collected using aseptic procedure. Considering localising signs and symptoms, various samples like blood, respiratory secretions, urine and wound swabs were collected. The samples obtained were processed using standard bacteriological techniques for microscopy and culture. Antibiotic susceptibility testing of isolate mainly for the first line antibiotics and those used in prophylaxis was done by Kirby-Bauer method.(5)

\section{Data Analysis}

The filled questionnaires were cross-checked for completeness of data by authors before entering into SPSS version 20 for data analysis. Descriptive statistics (percentage, frequency, mean, median, etc.) were used to describe the study sample. The associations between postoperative infection and study variable were investigated using Chi-square test. P-values $<0.05$ were considered significant.

\section{RESULTS}

Of the total 100 patients included in the study, $22(22.0 \%)$ patients developed postoperative infections. Of the total person who developed any type of infection close to $33.0 \%$, patients developed postoperative infections during the follow-up visits (within 30 days) after discharge from the hospital.
The most common type of postoperative infection was surgical site infections. In numerical terms, a total of $14 \%$ patients suffered from surgical site infections either at sternal site or leg harvest site. Only 3 patients developed deep-seated infections. Urinary tract infections were the second most common infections in hospitalised patients. All urinary tract infections were catheter associated and occurred predominantly in females. The respiratory tract infection and blood stream infection occurred in 3 patients each.

Table 2 summarises the proportion of postoperative infection and the type of cardiac surgery performed on patients. The three most common bacteria isolated from the postoperative infection were Pseudomonas aeruginosa, Staphylococci and Enterobacteriaceae. Various risk factors associated with development of postoperative infections in cardiac surgeries patients are summarised in Table 4.

\begin{tabular}{|c|c|c|}
\hline Type of Infection & $\begin{array}{l}\text { No. of Infected } \\
\text { Patients (n) }\end{array}$ & $\%$ \\
\hline $\begin{array}{c}\text { Surgical site infection } \\
\text { (sternal site + leg harvest site) }\end{array}$ & 14 & 14.0 \\
\hline Urinary tract infection & 6 & 6.0 \\
\hline Respiratory tract infection & 3 & 3.0 \\
\hline Bloodstream infection & 3 & 3.0 \\
\hline No infection & 74 & 74.0 \\
\hline \multicolumn{3}{|c|}{$\begin{array}{l}\text { Table 1. Distribution of Study Participants Based } \\
\text { on the Types of Infections Observed }(n=100)\end{array}$} \\
\hline
\end{tabular}

\begin{tabular}{|c|c|c|c|c|c|c|}
\hline Type of Surgery & Total Patients & Infected Patients n (\%) & SSI & UTI & RTI & BSI \\
\hline Mitral valve replacement & 30 & $5(16.66)$ & 3 & 3 & - & - \\
\hline Atrial septal defect closure & 21 & $3(14.28)$ & 1 & 2 & - & - \\
\hline Coronary artery bypass grafting & 19 & $8(42.10)$ & 6 & 1 & 2 & 2 \\
\hline Closed mitral valvotomy & 7 & - & - & - & - & - \\
\hline Total correction of tetralogy of Fallot & 6 & $3(50)$ & 2 & - & - & 1 \\
\hline Patent ductus arteriosus ligation & 6 & - & - & - & - & - \\
\hline Aortic valve replacement & 5 & $1(20)$ & 1 & - & - & - \\
\hline Double valve replacement & 4 & $2(50)$ & 1 & - & 1 & - \\
\hline Open mitral valvotomy & 3 & - & - & - & - \\
\hline Ventricular septal defect & 1 & - & - & - & - & - \\
\hline Pulmonary valvotomy & 1 & - & - & - & - \\
\hline Total & $\mathbf{1 0 0}$ & $\mathbf{2 2}$ & $\mathbf{6}$ & $\mathbf{3}$ & $\mathbf{3}$ \\
\hline SSI- Surgical site infections, UTI- Urinary tract infection, RTI- Respiratory tract infection, BSI- Blood stream infection \\
\hline Table 2. Distribution of Study Participants by the Type of Cardiac Surgery and Postoperative Infections (n=100) \\
\hline
\end{tabular}

A Few patients have undergone more that one surgical procedures out of total 100 patients.

\begin{tabular}{|c|c|c|c|c|c|c|c|}
\hline \multirow{2}{*}{ Isolates } & \multicolumn{2}{|c|}{ SSI } & \multirow{2}{*}{ UTI } & \multirow{2}{*}{ RTI } & \multirow{2}{*}{ BSI } & \multirow{2}{*}{ Total } & \multirow{2}{*}{$\%$} \\
\hline & Sternal & Leg & & & & & \\
\hline Pseudomonas aeruginosa & 5 & 1 & 2 & 1 & - & 9 & 23.07 \\
\hline Coagulase-negative staphylococci & 4 & 1 & 1 & & 1 & 7 & \\
\hline Methicillin resistant & 3 & - & 1 & - & 1 & 5 & 17.95 \\
\hline Methicillin sensitive & 1 & 1 & - & & - & 2 & \\
\hline Staphylococcus aureus & 2 & 1 & 1 & 1 & 1 & 6 & \\
\hline Methicillin resistant & 1 & - & 1 & 1 & - & 3 & 15.38 \\
\hline Methicillin sensitive & 1 & -1 & - & - & 1 & 3 & \\
\hline Klebsiella pneumonia & 3 & - & 1 & 1 & 1 & 6 & 15.38 \\
\hline Escherichia coli & 1 & 1 & 2 & - & - & 4 & 10.25 \\
\hline Proteus mirabilis & 2 & - & - & - & - & 2 & 5.13 \\
\hline Proteus vulgaris & - & - & 1 & - & - & 1 & 2.56 \\
\hline Nonfermenter gram-negative bacilli & 1 & - & 1 & - & - & 2 & 5.13 \\
\hline Acinetobacter spp. & 1 & - & - & - & - & 1 & 2.26 \\
\hline Streptococcus pyogenes & - & - & - & 1 & - & 1 & 2.26 \\
\hline
\end{tabular}




\begin{tabular}{|c|c|c|c|c|c|}
\hline Risk Factor & Total Patients & Infected Patients & $\%$ & Chi-Square Statistics & P Value \\
\hline \multicolumn{6}{|c|}{ Age } \\
\hline $0-15$ & 20 & 2 & 10 & \multirow{3}{*}{3.5} & \multirow{3}{*}{0.041} \\
\hline $16-45$ & 61 & 12 & 19.67 & & \\
\hline$>45$ & 19 & 8 & 42.1 & & \\
\hline \multicolumn{6}{|c|}{ Gender } \\
\hline Male & 44 & 11 & 25 & \multirow{2}{*}{0.74} & \multirow{2}{*}{0.092} \\
\hline Female & 56 & 11 & 19.64 & & \\
\hline \multicolumn{6}{|c|}{ Body Mass Index (in kg/m²) } \\
\hline$<25$ & 60 & 12 & 20 & \multirow{3}{*}{4.8} & \multirow{3}{*}{0.029} \\
\hline $25-30$ & 27 & 5 & 18.51 & & \\
\hline$>30$ & 13 & 5 & 38.46 & & \\
\hline \multicolumn{6}{|c|}{ Diabetes Mellitus } \\
\hline Yes & 3 & 1 & 33.33 & \multirow{2}{*}{1.52} & \multirow{2}{*}{0.047} \\
\hline No & 97 & 21 & 21.64 & & \\
\hline \multicolumn{6}{|c|}{ Smoking } \\
\hline Yes & 5 & 2 & 40 & \multirow{2}{*}{0.72} & \multirow{2}{*}{0.078} \\
\hline No & 95 & 20 & 21.05 & & \\
\hline \multicolumn{6}{|c|}{ Type of Operation } \\
\hline Coronary artery bypass grafting & 19 & 8 & 42.1 & \multirow{3}{*}{0.64} & \multirow{3}{*}{0.09} \\
\hline Valve surgery & 49 & 8 & 16.32 & & \\
\hline Surgery for congenital heart disease & 35 & 6 & 17.14 & & \\
\hline \multicolumn{6}{|c|}{ Duration of Surgery } \\
\hline$\leq 6$ hours & 88 & 16 & 18.18 & \multirow{2}{*}{1.89} & \multirow{2}{*}{0.041} \\
\hline$>6$ hours & 12 & 6 & 50 & & \\
\hline \multicolumn{6}{|c|}{ Blood Transfusion } \\
\hline$\leq 4$ units & 28 & 6 & 21.42 & \multirow{2}{*}{0.81} & \multirow{2}{*}{0.071} \\
\hline$>4$ units & 72 & 16 & 22.22 & & \\
\hline \multicolumn{6}{|c|}{ Mechanical Ventilation } \\
\hline$\leq 6$ hours & 70 & 10 & 14.28 & \multirow{2}{*}{0.79} & \multirow{2}{*}{0.074} \\
\hline$>6$ hours & 30 & 12 & 40 & & \\
\hline Table 4. Compar & nof Presence of & isk Factors in Infe & and $U n$ & fected Patients & \\
\hline
\end{tabular}

\section{DISCUSSION}

Surgery induces systemic and local changes in the immune defense mechanisms of the host. Cardiac surgery causes considerably greater stress on the host defenses. In cardiac surgery, the patient may be exposed to hypothermia, cardiopulmonary bypass, relative arterial hypotension throughout much of the procedure and the use of one or both internal mammary arteries for grafting. Exposure of blood to cardiopulmonary bypass depletes serum complements and immunoglobulins. Furthermore, protein denaturation and chylomicron aggregation may contribute to small vessel occlusion and tissue hypoxia. In the setting of hypothermia, neutrophils have reduced chemotaxis, impaired phagocytosis of Staphylococci and diminished peroxide production. $(6,7)$

Nosocomial infections following cardiac surgery are associated with prolonged hospitalisation, development of multiorgan dysfunction and increased hospital morbidity and mortality.(8) Understanding the epidemiology of these infections and the risk factors associated with them will prove to be of utmost importance in the prevention of these infections.

The incidence of postoperative infections following cardiac surgery in this study was found to be $22 \%$ with surgical site infections being the commonest. None of the patients suffered from prosthetic valve endocarditis or organ space infections like mediastinitis during the study period.

Pseudomonas aeruginosa was the commonest organism and constituted $23.07 \%$ of total isolates. It was mainly recovered from infections of wounds and urinary tract. The antibiotic prophylaxis in cardiac surgery patients being directed mainly against staphylococci might be responsible for this. Coagulase-negative Staphylococci and Staphylococcus aureus were the next most common organisms mainly isolated from surgical sites. The other isolates were enteric bacteria, mainly Klebsiella species, Escherichia coli and others.

Gram-positive organisms showed resistance to penicillin, cefazolin and oxacillin, whereas gram-negative organisms were mainly resistant to ampicillin, gentamycin and amikacin. Both of them were found to show resistance to cotrimoxazole, tetracycline and ciprofloxacin. Majority of resistant organisms were isolated from patients during their hospital stay indicating that these organisms were hospital acquired.

As all the urinary tract infections were catheter associated, which was removed by fifth postoperative day, these infections were observed in the early postoperative period only. Blood stream infections also tended to occur in the early postoperative period, which may be due to seeding of organisms from skin, bypass machine and other invasive devices into blood circulation.

Wound infections were rarely seen in the first postoperative week and mainly observed in second week up to $15^{\text {th }}$ postoperative day. This might be due to use of antibiotics at local site during operation and intravenous antibiotics in the early postoperative period.

The percentage of infection in patients $>45$ years of age is $42.1 \%$ as compared to $10-20 \%$ in younger patients. As with other reports, systemic infections like respiratory and bloodstream infections were more common in the elderly patients. $(9,10)$ Whereas in the younger age group, surgical site 
and urinary tract infections were more frequently observed. However, no significant difference in the incidence of infection in male and female patients was observed.

The incidence of infection in obese patients (BMI $>30$ $\mathrm{kg} / \mathrm{m} 2$ ) was almost double of that observed in non-obese patients. The possible reasons for it include ineffective distribution of prophylactic antibiotics, adipose tissue providing good nidus for infection and difficulty in vascular graft harvesting.(1)

Infected patients had considerably longer preoperative hospital stay (median 14 days) as compared to uninfected ones (median 8 days). The longer hospital stay may lead to patients being exposed to resistant strains in hospital environment that are less sensitive to agents used for prophylaxis.

The rate of infection in patients undergoing CABG surgery was much greater than that those undergoing valvular heart disease surgeries. This may be due to the fact that patients undergoing CABG were usually elderly and had multiple surgical wound superadded with other risk factors.

Infections occurred much more commonly in patients with operative time of $>6 \mathrm{hrs}$. as compared to those with $<6$ hrs. Contamination of surgical field is likely to be time related and also prolonged operations can be complicated predisposing patients to infections.(1) Also, mechanical ventilation for $>6 \mathrm{hrs}$. was also associated with increased incidence of infection in the present study.

Diabetic patients are at increased risk of developing infections due to compromised host defence mechanisms.(1,9,11) Current cigarette smoking also predisposes to infection by causing vasoconstriction.(12) Although, increased incidence of infections were found in these patients, very few of them had these risk factors and hence these variables could not be reasonably assessed as risk factor.

The present study had the limitation of not being able to assess all the risk factors reported to be associated with development of infection in the cardiac surgery patients.

\section{CONCLUSION}

The incidence of infection in cardiac surgery patients was $22 \%$. Various types of infections observed were wound infections- $14 \%$, urinary tract infections- $6 \%$, respiratory tract infections- 3\% and blood stream infections- 3\%. The commonest isolate was Pseudomonas aeruginosa followed by CONS and Staphylococcus aureus. Age $>45$ years, obesity, surgery for $\mathrm{CABG}$, operative time of $>6 \mathrm{hrs}$. and mechanical ventilation for $>6 \mathrm{hrs}$. were associated with increased incidence of infection.
Despite numerous advances in surgical techniques and antibiotic treatments, infections following cardiac surgeries are difficult to treat. Thus, prevention by reducing modifiable risk factors and implementing proper infection control practices seems to be a best course of action.

\section{REFERENCES}

[1] Bhatia JY, Pandey K, Rodrigues C, et al. Postoperative wound infections in patients undergoing bypass graft surgery: a prospective study with evaluation of risk factors. IJMM 2003;21(4):246-51.

[2] Kollef MH. Ventilator associated pneumonia. A multivariate analysis. JAMA 1993;270(16):1965-70.

[3] Beck-Sague CM, Sinkowitz RL, Chinn RY, et al. Risk factors for ventilator-associated pneumonia in surgical intensive care unit patients. Infect Control Hosp Epidemiol 1996;17(6):374-6.

[4] Gustafasson R, Johnson P, Algotsson L, et al. Vacuum assisted closure therapy guided by C-reactive protein level in patients with deep sternal wound infections. J Thorac Cardiovasc Surg 2002;123(5):895-900.

[5] Collec JK, Duguid JP, Eraser AG, et al. Marmon BP: Laboratory strategy in the diagnosis of infective syndromes. 14th edn. In: Mackie and McCartney's practical medical microbiology 2007.

[6] Kernodle DS, Kaiser AB. Postoperative infections and antimicrobial prophylaxis. $4^{\text {th }}$ edn. In: Mandell GL, Bennet JE, Dolin R. Principles and practice of infectious diseases. Vol 2, 1995:2742-56.

[7] Stein PD, Dwight HF, Dexter L, et al. The nature and prevention of prosthetic valve endocarditis. Am Heart J 1996;71(3):393-407.

[8] Kollef MH, Sharpless L, Vlasnik J, et al. The impact of nosocomial infections on patient outcomes following cardiac surgery. Chest 1997;112(3):666-75.

[9] Nelson RM, Dries DJ. The economic implications of infection in cardiac surgery. Ann Thorac Surg 1986;42(3):240-6.

[10] Simchen E, Shapiro M, Marin G, et al. Risk factors for post-operative infection in cardiac surgery patients. Infect Control 1983;4(4):215-20.

[11] Zacharias A, Habib RH. Factors predisposing to median sternotomy complications. Deep vs. superficial infections. Chest 1996;110(5):1173-8.

[12] Nagachinta T, Stephens M, Reitz B, et al. Risk factors for surgical wound infection following cardiac surgery. J Infect Dis 1987;156(6):967-73. 